\title{
Humanity in Medicine
}

\author{
Pankaj Gupta
}

Resident Medical Officer. Department of Preventive and Social Medicine, Seth G. S. Medical College and K.E.M Hospital, Mumbai, Maharashtra, India.

Mailing address: A-9, Landmark CHS, Plot no. 2-1 and 2-8, Sector 14, Vashi, Navi Mumbai, Maharashtra, India - 400703.

Email: pankajgupta85@rediffmail.com

Received: 09 Jan 2011

Accepted: 20 Feb 2011

Published: 27 Feb 201I

J Med Ethics Hist Med, 20I I, 4:3

(C) 20II Pankaj Gupta; licensee Tehran Univ. Med. Sci.

"To most physicians, my illness is a routine incident in their rounds, while for me it's the crisis of my life. I would feel better if I had a doctor who at least perceived this incongruity" - Anatole Broyard (Former New York Times critic) (1).

My first brush with the issue of humanity in medical field was when I read this quote, a few months back, put up by a prestigious international journal for an essay writing competition.

As I read that quote, it stirred my conscience. And although I almost instantaneously quelled the desire to write on it, thinking my chances of winning an essay contest too slim to bother with, it set me thinking. The idea behind this quote is thought provoking. It challenges those of us in the medical field to remember what it feels like to be on the other end of the stethoscope - to remember that there is a person and not just a pathogen infecting a host. The purpose behind my presentation of ideas on this platform is to reinforce upon us, healthcare professionals, the importance of rekindling and keeping alive the desire of service to mankind with which many of us had gone into the medical profession.

\section{My experiences with humanity in medicine:}

My father, on my first day of medical school, had put his arm around my shoulder and said "Son, always remember that the secret to the care of the patient is in caring for the patient”. I, an exuberant 17 year old, with admission letter in my hand and an innocent heart overflowing with an overpowering desire to "serve the mankind", made quick mental note of what my father had to tell me. Little did I realize that a couple of years later the patients I wanted to "serve" would be reduced to "an excellent hemiplegia case” or "a great hernia case”.

By saying "excellent” and "great”, I was not, in any way, wishing ill for the patient. I was just describing my visceral reaction to a case which I could learn new concepts from. From a medical perspective, when we are faced with routine everyday conditions, something unusual and dramatic is, well really cool. To the patient, however, it is anything but that. But who cares? Once the "excellent" case was presented to the lecturer in the all important "clinic", the "case" was forgotten in haste. Over to the next case!!!

After struggling through the arduous final year exams, I finally became an intern, (a surrogate term for blood sucking vampire, because the only work remotely related to medicine I did was blood sample collection). My entire world centered on "veins", so much so that patients were subconsciously classified as those having "good veins" and those having "difficult veins"; and those who "cooperated" and those who "did not cooperate"; and those who were "screamers" and the sweet ones who were "non screamers". It was the sheer drudgery of the job which sucked out all feelings from me and forced me to think so.

The Emergency room is another such place where there is an inadvertent neglect of humanity. When your work involves the dying and those who grieve for them, the skill of keeping the humor alive becomes vitally important. We do indulge in humor all the time in the emergency room (ER), and if the general public could see it, they would be horrified. We would look like insensitive people 
who feast on pain. Again there is no malicious intent here on the part of the doctor; it is a simple defense mechanism. We doctors explain it as, "I'm laughing to keep from crying." It helps keep you somewhat whole and functional, and allows you to carry on and do your job - questionable in terms of taste and professionalism, but necessary and actually helpful on the whole. If you were a blubbering wreck because you just had to amputate someone's limb due to gangrene, you would be less able to help the next patient in line.

\section{Disappearing humanism in medical practice: Why?}

Hippocrates had said "Medicine is an art". Whether I believe him or not is no issue, but the examiner who sets the paper for the entrance exam in medical field surely doesn't think so. If he did, why does he want to know how much of inorganic chemistry, botany and mechanics, I am aware of? Shouldn't an aspiring doctor be assessed about his emotional intelligence and sensibilities, rather than carrying out futile exercises to quantify his capability to mug up vague theories? Pre-medical exams do not develop scientific logic and skill; they only encourage and identify competitive memorizers. The science-only policy is not only restrictive but also selects many candidates with limited aptitude for medical practice.

In medical school, the fashionable focus on biology and the reduced emphasis on social determinants of health make physicians shortsighted and leave them without an understanding of long-term solutions to common diseases. The spotlight on pathology and disease with a failure to understand illness and patient reality often leads to problems in communication, patient dissatisfaction and doctor shopping. The absence of communication and counseling skill training in the curriculum makes it difficult for doctors to convey bad news about diagnosis. The lack of training in negotiation skills for discussing treatment plans often results in poor compliance and medico-legal problems due to discrepancies between the views of patients and doctors on clinical reality.

The "science" of medicine is thus well taught in medical schools but the "art" of medicine is given a step motherly treatment in the medical curriculum. No student has ever got an extra mark in his case presentation for his friendly, polite and endearing mannerism towards the patient! And we in the medical fraternity can never think beyond marks!!

\section{Humanity in medicine - My perspective}

Writing in Academic Medicine in 2009, Shapiro et al. observed that there is an "ongoing lack of clarity on what exactly the medical humanities comprise, and how they should be integrated into medical education." They proceeded to offer a narrowly "pedagogical" definition: the medical humanities use the methods and concepts of one or more of the humanities disciplines, teach students critical reflection aimed toward a more humane practice, and are by nature interdisciplinary and collaborative (2). Another approach was suggested in 2008, when Evans identified three "manifestations" of medical humanities: as an academic field of intellectual inquiry, as a dimension of medical education, and as "...a source of moral and aesthetic influence upon the daily praxis of organized clinical health care" (3). Way too complicated for a person like me with a juvenile horizon of thinking!!! My heart gives me a better definition of humanity in medicine - it is caring for a patient as one would care for his or her loved one. I am sure to find acknowledgement from the Nobel laureate, Bharat Ratna Mother Teresa. She once had a foreign visitor who remarked that he would never touch a leper's wounds even if he was offered a million dollars. Mother lovingly replied that even she wouldn't do that for a million dollars; she would do that only because of her love and service for Jesus Christ.

If we accept that medicine is an interpretive science and that the most reliable patient with clear-cut symptoms is a potentially uncertain field of knowledge, then it follows that attention must be given to patients' cultural, social, and family contexts. This allows a more nuanced interpretation of the patients' narratives, the meaning they attribute to their experiences, their values, and their beliefs, and it helps to ensure a successful therapeutic relationship. Medical humanities provide anthropological, historical, and literary tools that allow us to use the underlying cultural context to identify the range of possible interpretations of a given situation.

Humanity in medicine shares an intimate connection with the concept of physician-patient relationship. Societal changes and ethical issues in health care have been responsible for the evolution of the models of the physician-patient relationship today. The role of the physician is to maintain patient autonomy, maintain and/or improve health, promote good, do no evil, and to create a relationship based on trust. The key ethical principles of respect for persons, autonomy (self-determination), beneficence (do good), non-maleficence (avoid evil), justice (allocation of resources), and veracity (truthfulness) should be inclusive in the physicianpatient relationship.

The quality of this relationship is important to both, doctors and patients. The better the relationship in terms of mutual respect, knowledge, trust, shared values and perspectives about disease and life, and time available, the better will be the amount and quality of information about the patient's disease transferred in both directions, enhancing accuracy of diagnosis and increasing the 
patient's knowledge about the disease. Where such a relationship is poor the physician's ability to make a full assessment is compromised and the patient is more likely to distrust the diagnosis and proposed treatment, causing decreased compliance to actually follow the medical advice. In these circumstances and also in cases where there is genuine divergence of medical opinions, a second opinion from another physician may be sought or the patient may choose to go to another doctor.

Our work in medicine often exposes us to the darker side of human existence. On virtually every shift we get exposed to the seamy underbelly of life. There is homelessness, drug addiction, abuse, neglect, trauma, and lots for our psyche to absorb. This is to say nothing of the strokes, pneumonias, heart attacks, fractures, miscarriages, and more common daily woes that plague our species. Keeping a humane outlook amidst all this is indeed a difficult job, but that's what humanism in medicine is all about!

\section{What can be done?}

I am convinced of the need of incorporation of humanities in the medical curriculum. The "Why" part has already been discussed; more pertinent now is to ask "How" - How do we go about this amalgamation of humanities training in medical schools. I am hugely impressed with the training program designed by University of Geneva School of Medicine (4). The training program has the following goals directed to developing the following skills among medical students:

- Contextualizing a patients clinical condition in the background of his socio-demographics, family and culture

- Developing personal reflection and judgment which can sharpen, cultivate, or revive students' curiosity, and enhances intellectual and relational capacities

- Encouraging imagination to gain a better understanding of how others perceive and experience things

- Offering specific ways to improve the quality of the therapeutic relationship by creating explicit links between the first three goals and day-today medical practice
Tools which can be used are seminars, role plays and internships. Seminars and role plays should cover the dynamics of medical consultation, repercussions of illness on the patient, family and society; handling a dying patient and also handling of personal frustrations and pressures of the doctors themselves.

Providing textured demonstration of humanistic values through methods such as critical incident reports (5) and creative projects (6), as well as the use of humanistic connoisseurs (7) to mentor and formatively evaluate learners are some suggested measures to gradually incorporate humanities in medical curriculum. It is well established in the research literature that role modeling is among the strongest influences on medical students' learning (8). Medical humanities faculty can play a key role in helping interested physicians become more effective in manifesting humanistic skills and values in their teaching, by serving as role models (9).

It would be pretentious to believe that such a program alone will change medical practice. However, the vision is to provide students with tools that are specific to humanities so they can strengthen their own judgment, listening skills, open-mindedness, creativity, and curiosity. These attributes are needed to ensure that the therapeutic relationship will be satisfying for both doctors and patients.

\section{Final thoughts}

The process of writing this article has drawn my attention to the advice of my mother. She says that the medical values of doctors should be based on 'Nishkama Karma', expounded by Bhagvadgita (ancient Indian religious text). Nishkama Karma, or self-less or desireless action is an action performed without any expectation of fruits or results, and the central tenet of path to liberation according ancient Indian ideology. Only through "Nishkama Karma”, we will be able to truly nurture and nourish humanity in our profession. Only then can we hope to give a resounding answer to Voltaire's caustic comments on doctors - "Doctors are men who prescribe medicines of which they know little, to cure diseases of which they know less, in human beings of whom they know nothing."

\section{References}

1. Broyard A. Doctor talk to me. The New York Times. 1990. http://www.nytimes.com/1990/08/26/magazine/doctor-talkto-e.html?pagewanted=5

2. Shapiro J, Coulehan J, Wear D, Montello M. Medical humanities and their discontents: definitions, critiques, and implications. Acad Med 2009; 84: 192-8.

3. Evans HM. Affirming the existential within medicine: medical humanities, governance, and imaginative understanding. $\mathrm{J}$ Med Humanit 2008; 29: 55-9. 
4. Louis-Courvoisier M. Medical humanities: a new undergraduate teaching program at the University of Geneva School of Medicine, Switzerland. Acad Med 2003; 78(10): 1043-7.

5. Misch DA. Evaluating physicians' professionalism and humanism: The case for humanism connoisseurs. Acad Med 2002; 77: 489-95.

6. Branch WT Jr. Use of critical incident reports in medical education. A perspective. J Gen Intern Med 2005; 20: $1063-7$.

7. Rucker L, Shapiro J. Becoming a physician: students' creative projects in a third-year IM clerkship. Acad Med 2003; 78: 391-7.

8. Jones WS, Hanson JL, Longacre JL. An intentional modeling process to teach professional behavior: Students' clinical observations of preceptors. Teach Learn Med 2004; 16: 264-9.

9. Wright SM, Kern DE, Kolodner K, Howard DM, Brancati FL. Attributes of excellent attending physician role models. N Engl J Med 1998; 339: 1986-93. 